\title{
Unexpected difficulty in ventilating the lungs after tracheal intubation
}

\section{-A case report-}

\author{
Jong-Yeon Lee, Su-Yeon Lee, Inho Shin, Kum-Hee Chung, and Duk-Hee Chun \\ Department of Anesthesiology and Pain Medicine, CHA Bundang Medical Center, CHA University, Seongnam, Korea
}

We experienced difficulty in ventilating the lungs of a patient after tracheal intubation. After intubation, an insufficient amount of tidal volume $\left(\mathrm{V}_{\mathrm{T}}\right)$ was delivered to the patient and the fiberoptic bronchoscopic examination identified partial abutment of the endotracheal tube (ETT) orifice against the tracheal wall. After various attempts to correctly place the ETT, a double-lumen endotracheal tube was placed to achieve a sufficient $\mathrm{V}_{\mathrm{T}}$. It is important to notice that even an appropriately placed ETT may get obstructed due to the left sided bevel at its tip. (Korean J Anesthesiol 2011; 60: 437-439)

Key Words: Airway obstruction, Bronchoscopy, Double lumen tube, Tracheal abutment.

Airway obstruction can cause serious problems during general anesthesia and an anesthesiologist must continuously monitor for the presence of airway problems during an operation. A failure to reach the target tidal volume $\left(\mathrm{V}_{\mathrm{T}}\right)$ must be thoroughly investigated before the operation starts. We present here a case where abutment of the endotracheal tube (ETT) against the tracheal wall was resolved by placing a doublelumen ETT.

\section{Case Report}

A 31-yr-old, $174 \mathrm{~cm}, 92 \mathrm{~kg}$ male was admitted after sustaining a C7 fracture due to a fall down injury. Magnetic resonance imaging revealed a bursting fracture with multiple bony fragmentations of the $\mathrm{C} 7$ vertebral body along with spinal canal stenosis and compression of the spinal cord. The patient was scheduled for emergency anterior cervical corpectomy and fusion, with being placed in the supine position, for the unstable bursting fracture and the incomplete cervical cord injury.

The patient had no known history of chronic obstructive pulmonary disease, asthma or chronic respiratory diseases. Routine anesthetic monitors were applied at the operating room, and anesthesia was induced with remifentanil, propofol and rocuronium. Face mask ventilation was successful with the capnographic tracing showing the end-tidal $\mathrm{CO}_{2}$ to be around $35 \mathrm{mmHg}$, the $\mathrm{V}_{\mathrm{T}}$ was $500-600 \mathrm{ml}$ and the peak airway pressure was around $20 \mathrm{cmH}_{2} \mathrm{O}$. The patient's trachea was intubated

Received: November 22, 2010. Revised: 1st, December 18, 2010; 2nd, January 5, 2011. Accepted: January 6, 2011.

Corresponding author: Duk-Hee Chun, M.D., Department of Anesthesiology and Pain Medicine, CHA Bundang Medical Center, CHA University, 351, Yatap-dong, Bundang-gu, Seongnam 463-712, Korea. Tel: 82-31-780-5643, Fax: 82-31-701-9433, E-mail: leah1013@chamc.co.kr (c) This is an open-access article distributed under the terms of the Creative Commons Attribution Non-Commercial License (http:// creativecommons.org/licenses/by-nc/3.0/), which permits unrestricted non-commercial use, distribution, and reproduction in any medium, provided the original work is properly cited. 
orally using a reinforced 8.0-mm ETT using the Lightwand (Surch-Lite $^{\mathrm{TM}}$, Aaron Medical Industry, St.Petersburg, FL, USA). Ausculatatory bilateral breath sounds could not be confirmed and the ETT was removed due to the suspicion of having intubated the esophagus. The ETT was reinserted by using the Lightwand and diminished, coarse breath sounds were auscultated distally. Capnography also showed the partial pressure of $\mathrm{CO}_{2}$, and so the ETT was secured at the $23 \mathrm{~cm}$ mark at the patient's upper incisors and the patient's lungs were mechanically ventilated with a $\mathrm{V}_{\mathrm{T}}$ of $750 \mathrm{ml}$ without positive end-expiratory pressure (PEEP). Yet the ventilator was able to deliver a $\mathrm{V}_{\mathrm{T}}$ of only $500 \mathrm{ml}$ with a peak inspiratory airway pressure (PIP) of $35 \mathrm{cmH}_{2} \mathrm{O}$. The limit of PIP was reset to 45 $\mathrm{cmH}_{2} \mathrm{O}$ without any increase in the $\mathrm{V}_{\mathrm{T}}$. A suction catheter was easily passed through the ETT and thick secretions were suctioned, but there still was no change in the $\mathrm{V}_{\mathrm{T}}$ or PIP. We decided to change the reinforced ETT to a plain ETT due to the suspicion of a mucous plug. Also the presence of a 'Murphy eye' on the plain ETT would decrease the risk of occlusion. This time tracheal intubation was performed under direct laryngoscopy in order to confirm an appropriate depth of the ETT. The patient's lungs were mechanically ventilated, but the PIP was still high and the $\mathrm{V}_{\mathrm{T}}$ was still low. Eight $\mathrm{cmH}_{2} \mathrm{O}$ PEEP was added, the mode of the ventilator was changed from CMV to PCV with the pressure set at $40 \mathrm{cmH}_{2} \mathrm{O}$ and endotracheal suction was done, but there was no improvement.

Fiberoptic bronchoscopic (FOB) examination identified that the bevel of the ETT orifice was abutting against the tracheal wall (Fig. 1). To get the tube at the right position, first the patient's neck was positioned to the surgical position (neck

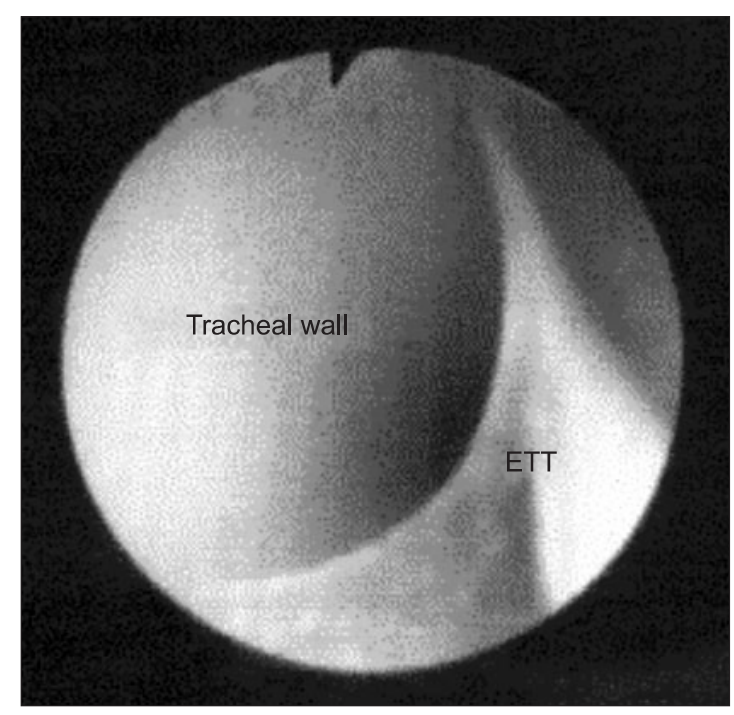

Fig. 1. The illustration of the bronchoscopic view of the trachea shows the bevel of the endotracheal tube abutting on the left side of the tracheal wall. ETT: endotracheal tube. extension) and then the ETT was withdrawn $1 \mathrm{~cm}$. Despite that the tip of the ETT and the wall of trachea were abutting to one another, we kept withdrawing the ETT under FOB examination. When the ventilator was turned on, the $\mathrm{V}_{\mathrm{T}}$ was still low and the endoluminal view under FOB remained unchanged. We next tried to rotate the ETT since the patient's head could not be rotated due to the surgical position. The ETT was turned $90^{\circ}$ counterclockwise to disengage the bevel from the tracheal wall, but the tip of ETT was not turned and we tried to rotate the ETT $180^{\circ}$, but the ETT became kinked instead.

We determined that a single lumen ETT tracheal tube could not be positioned properly and so a double-lumen ETT was placed. The PIP immediately dropped from 48 (CMV mode) to $23 \mathrm{cmH}_{2} \mathrm{O}$ with a $\mathrm{V}_{\mathrm{T}}$ of $750 \mathrm{ml}$. Bilateral breath sounds were confirmed and the end-tidal $\mathrm{CO}_{2}$ was normalized. The PIP remained stable throughout the surgical period and the patient's trachea was extubated at the end of surgery.

\section{Discussion}

In neonates, the distal orifice of an uncuffed ETT abuts against the tracheal wall and causes frequent obstruction at the end of the ETT $[1,2]$. But for adults, a cuffed ETT does not allow free movements of the ETT in the trachea and obstruction does not occur as often as that in young babies. Numerous reports exist concerning tube-tip displacement during head-neck movement in children [3-5]. Head movement shifts the secured ETT within the trachea and causes downward movement during neck flexion and upward movement during neck extension [6]. Yet for adults, unknown anatomical anomaly seems to cause tube malposition or difficulty in ventilation [7-9]. The reported cases of patients with a tracheal bronchus emphasize the importance

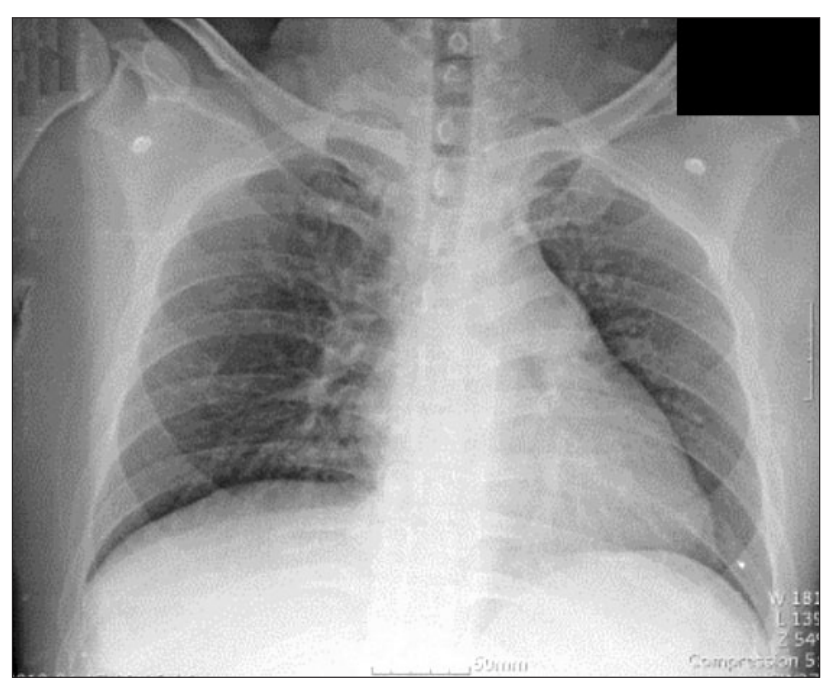

Fig. 2. The preoperative chest radiograph shows no tracheal deviation. 
of correct positioning of the ETT $[7,8]$. In this case, the patient did not have any anatomical abnormality that would cause difficulty when ventilating the lungs.

Togashi et al. [9] reported a case of a tube orifice abutting on the tracheal wall in a patient with Forestier's disease. Due to large osteophytes of the cervical vertebral bodies of C5, 6 and 7 , the trachea was deviated on extension of the neck and this caused the bevel of the tube to abut against the tracheal wall. The $\mathrm{C} 7$ fracture with multiple bony fragmentation of the $\mathrm{C} 7$ vertebral body in our patient might have caused some anatomical alteration, which could have caused the difficulty in ventilation. Yet there was no obvious tracheal deviation seen on the preoperative chest x-ray (Fig. 2). Further, the difficulty to ventilate the lungs did not improve or worsen because of head extension.

Jordi Ritz et al. [4] mentioned that inadvertent tube malposition occurs more often with pre-formed tubes when compared to that for straight tubes. It seems that the curvature of the ETT was angled in such a way that the beveled tip of the ETT and the wall of trachea embraced tightly to each other, and not enough $V_{T}$ was delivered to the patient. We also did not suspect abutment of the ETT on the tracheal wall and it took a while to decide to perform an examination under FOB because $a V_{T}$ of $500 \mathrm{ml}$ was being delivered to the patient. It is important to notice that even an appropriately placed ETT may get obstructed due to its left sided bevel. It is still unclear why enough $\mathrm{V}_{\mathrm{T}}$ was not delivered to the patient when we changed the reinforced tube to a plain ETT with a Murphy eye. Probably a Murphy eye simply was not able to deliver a $\mathrm{V}_{\mathrm{T}}$ of $750 \mathrm{ml}$ and the surgical position (neck extension) did not assist in improving the $\mathrm{V}_{\mathrm{T}}$.

Once airway problems were encountered in an intubated patient, it is important to consider both mechanical and pathologic factors. Especially for this case, just enough $\mathrm{V}_{\mathrm{T}}$ was delivered to the patient and the problem could have been overlooked because the patient was obese (BMI > 30). FOB is a useful tool to confirm the position of the ETT and to correctly place it. Yet the most important thing for the anesthesiologist is to act as a thoughtful, thorough investigator. If there is any doubt about the airway, then one must evaluate the problem and meticulously manage it before the operation starts.

\section{References}

1. Donn SM, Kuhns LR. Mechanism of endotracheal tube movement with change of head position in the neonate. Pediatr Radiol 1980; 9: 37-40.

2. Brasch RC, Heldt GP, Hecht ST. Endotracheal tube orifice abutting the tracheal wall: a cause of infant airway obstruction. Radiology 1981; 141: 387-91.

3. Weiss M, Knirsch W, Kretschmar O, Dullenkopf A, Tomaske M, Balmer C, et al. Tracheal tube-tip displacement in children during head-neck movement--a radiological assessment. Br J Anaesth 2006; 96: 486-91.

4. Jordi Ritz EM, Von Ungern-Sternberg BS, Keller K, Frei FJ, Erb TO. The impact of head position on the cuff and tube tip position of preformed oral tracheal tubes in young children. Anaesthesia 2008; 63: 604-9.

5. Park HP, Jeon YT, Hwang JW, Jung TW, Park SC, Oh YS. Head and neck positional change causes the alteration in endotracheal cuff pressure. Korean J Anesthesiol 2006; 50: 54-9.

6. Hartrey R, Kestin IG. Movement of oral and nasal tracheal tubes as a result of changes in head and neck position. Anaesthesia 1995; 50: 682-7.

7. Sripada R, Keys K, Eichholz KM. Inability to ventilate the lungs of a patient with tracheal anomaly and in prone position. J Clin Anesth 2008; 20: 386-8.

8. Wong DT, Kumar A. Case report: Endotracheal tube malposition in a patient with a tracheal bronchus. Can J Anaesth 2006; 53: 810-3.

9. Togashi H, Hirabayashi Y, Mitsuhata H, Saitoh K, Shimizu R. The beveled tracheal tube orifice abutted on the tracheal wall in a patient with Forestier's disease. Anesthesiology 1993; 79: 1452-3. 